\title{
Theoretical model and finite element analysis for restoring moment at column foot during rocking
}

\author{
Junxiao $\mathrm{He}^{1} \cdot$ Juan Wang ${ }^{1}$
}

Received: 6 December 2016 / Accepted: 13 October 2017 / Published online: 19 December 2017

(c) The Japan Wood Research Society 2017

\begin{abstract}
Column usually rests directly on top of a stone base without any physical connection in traditional timber structures. When timber structure is subjected to horizontal loads, rotation around the edge of column foot may occur with or without slippage of column. Columns rock with cyclic lift and reset. Compression deformation occurs to column foot due to the heavy vertical load of the structure and it is an important factor to the loading bearing capacity of timber structure. Accordingly, the rotation behavior of column foot during rocking has to be taken into account when carrying out the structural analysis. For this purpose, rotation behaviors of column foot during rocking is studied, and theoretical model of restoring moment at column foot joint is proposed with consideration of the compression effect; finite element model is established to verify the proposed model and good agreement of the two models is found. Result shows that column foot has contributions to resist horizontal loads with rocking under lateral load.
\end{abstract}

Keywords Column foot $\cdot$ Theoretical model $\cdot$ Finite element analysis $\cdot$ Restoring moment $\cdot$ Compression

\section{Introduction}

Timber as a structural material may be found in many building and structures, especially in heritage structures [1]. Historical timber constructions are parts of cultural heritage that need to be maintained for generations [2]. Traditional timber structures are constructed of timber frameworks which can undertake significant deformation and dissipate a large amount of energy when taking up seismic load [3]. Different components of the timber structure are connected into the joints at the column foot and column head and the beam-column joints. These joints are the main load-carrying elements in a traditional wooden building and have top research priority [4]. Under horizontal loads, such as earthquake or wind loads, "column rocking" happened [5]. Restoring force characteristics of column rocking play major

Juan Wang

juanwang@bjtu.edu.cn

Junxiao He

14115289@bjtu.edu.cn

1 Beijing Key Laboratory of Structural Wind Engineering and Urban Wind Environment, School of Civil Engineering, Beijing Jiaotong University, No.3 Shang Yuan Cun, Hai Dian District, 100044 Beijing, China role in lateral resistance mechanism of the timber structure, and it may be indicated that as much as $70 \%$ of lateral strength of the building is given by the column rocking in a type of wooden ancient temple and shrine structures [6]. Experimental research on this subject was made by Ban [7]. Theoretical and experimental studies have been extensively made and clarified the static and dynamic features of the column rocking characteristics [8-10]. It is known that the restoring moment of a timber structure due to its deformation is a result of all bending moments at the top and bottom of columns during rocking, as well as those at beam-column joints due to resistance of tie beams [11]. Column foot joint at the bottom of the whole structure plays a crucial role on the restoring moment and structural behavior of timber structures, and it is without any physical connection and usually affects the internal force distributions in the whole structure. Hence, restoring moment and mechanical behavior of column foot joint during rocking are needed to be further studies.

More and more research interests have been devoted to the study of column in heritage buildings in recent years. Friction-sliding seismic isolation model has been proposed and the slippage criterion of a column foot is given [12]. It is assumed that the moment carried by the column foot is the same as that at the column head, and restoring moment 
at the column foot is determined according to the analytical moment at the top of column [13]. Lee et al. [14] proposes a technique for obtaining the skeleton curve of moment-rotation relation at the stone base of traditional timber buildings from local compression tests of wooden components. Those studies mainly focused on the friction-sliding characteristics, restoring moment of column head and stiffness characteristics of column. However, study on the whole process of column rocking under external loads is rare, and the rotational behaviors of column foot joint during rocking have not been studied. Furthermore, a recent trend in analyzing timber structures involves considering the timber connections as semi-rigid joints. But, few researches have focused on the semi-rigidity of column foot joint in traditional timer structure, and many studies take column foot as rigid or hinge joint during structural analysis. In fact, the rotation behavior of column foot needs to be better known to properly analyze the whole structure, and there is an urgent to study the mechanical behavior and propose a theoretical model for predicting the restoring moment and the rotational performance of column foot joint.

This paper tends to analyze the rotation behavior and performance of column foot joint in timber structure under horizontal load in detail. Resisting compression stress distributions at the interface are studied. Theoretical model of restoring moment for column foot joint is formulated with consideration of the compression effect and validated by finite element analysis.

\section{Rotation behaviors of column foot}

\section{Working states of column}

Columns in traditional timber structures are usually supported directly on the stone base. Example shown in Fig. 1 is the column foot in the Forbidden City in Beijing, China. The cross section of stone base is a little bigger than that of the column, which allows some slippage of the column foot [15] but not slipping off from the stone base. Under horizontal load, slip or rotation will happen, and column will become inclined with lifting and rotation about the edge of column foot, called "column rocking", which can resist the external force acting on the timber structure.

When vertical and horizontal loads are acting on the column, stone base will provide vertical reaction force as well as horizontal friction force to the column foot. The joint between column and stone base transmits compression force but no tensile force. If the horizontal load exceeds the friction force between column foot and stone base, slippage will occur at the column foot.

Under horizontal load, column may be in different working states. If the external horizontal load is zero, column

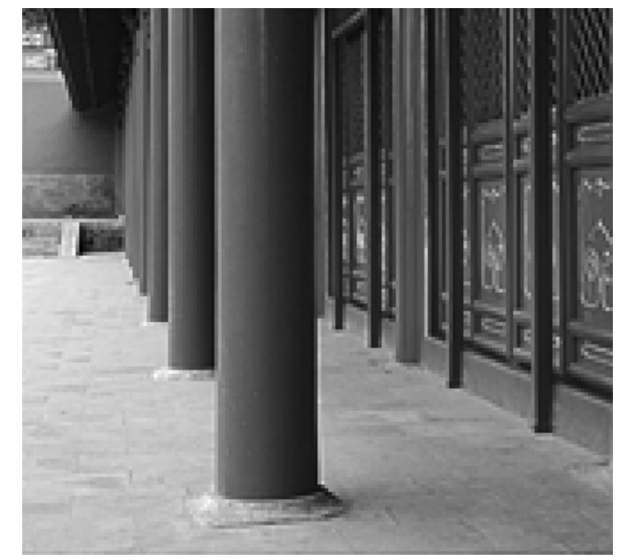

Fig. 1 Column foot

will not move, which is named as "full compression without slip". Under cyclic horizontal load, such as earthquake and wind, if the external force is less than the friction force at column foot, there is no relative displacement between column and stone base. Column foot transfer seismic energy all from the bottom of structure to upper structure. Column will rotate under the effect of horizontal load, which is named as "column rocking without slip". If the external force is larger than the friction force at column foot, slip will appear to the column foot. Column will rotate under the effect of horizontal load, which is named as "column rocking with slip". At this working state, the shear force at column foot is equal to the friction force according to the horizontal force equilibrium equation. And, the load transferred from the bottom of column foot to upper structure is same with friction force, which plays an obvious seismic isolation effects. After seismic load, column may be in a new state with irreclaimable slip, which is named as "full compression with slip". During column rocking, if the restoring moment is less than the external moment, column will overturn, which is named as "column overturning". Therefore, with the combined effects of vertical and horizontal loads, column may be in five possible working states: (a) full compression without slip; (b) full compression with slip; (c) column rocking without slip; (d) column rocking with slip and (e) column overturning. The force systems of column in working states (a) and (b) are clear. While the force systems of column in working states (c) and (d) under seismic load are not clear, which should be studied further.

"Chinese earthquake chronology" indicates that traditional timber structures have exhibited good resistance to large seismic excitations with small damages incurred. In the earthquake record of China, there are statements like "the wall collapsed but the structure stands" or "column foot removed but the whole structure is safe" [15]. The survival of traditional timber structure in a large earthquake with 
long duration indicates that the traditional timber structures are capable of maintaining stability over many cycles of excitations [16]. Therefore, detailed analysis on the deformation and the mechanical characteristics of the structure is needed. A study on the load-carrying mechanism of column foot in the state of column rocking without slip will lead to significant knowledge on the mechanical behaviors of column rocking with slip. This also provides a platform for developing the restoring moment model for the traditional timber structure under horizontal load.

\section{Compression deformation of column foot}

Joints in traditional timber structure resist external force by compression or embedment and friction to each member and show high ductility [17]. Such joints play an important role in the mechanical performance of traditional timber structures [18]. Compression deformation of timber at the bottom of the column is the main source of restoring force and moment in column foot joint [11]. During column rocking, compressive stress would occur at the contact interface between column and stone base due to the vertical load acting on the contact interface. Such distributions can be determined from the deformation and constitutive relation of timber at column foot as well as the changing of the contact interface as follows.

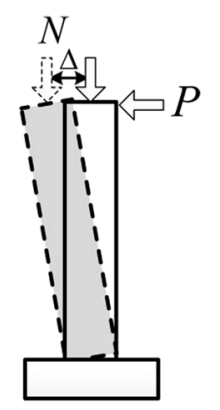

(a) Positive loading

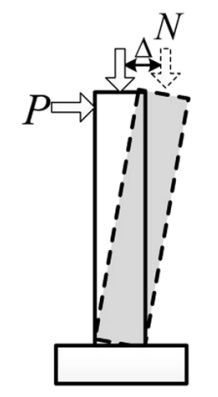

(b) Negative loading

\section{Compression effect}

Periodic loads such as seismic actions would induce column rocking existing in both Chinese and Japanese traditional timber structures. Column foot rotates about the column edge under horizontal load as shown in Fig. 2. Pivotal points of column foot may switch between the two opposite edges of column foot. Under cyclic horizontal load, column foots have compression deformations due to the heavy upper structure, and contact area between column foot and stone base are changing during column rocking. If horizontal force is not big enough, there is no lifting occurring to column foot, shown in Fig. 3. Compression interface is equal to the whole cross section of column foot shown in Fig. 4. If horizontal force is big enough, lifting on one side and compression on the other side would happen to the column foot shown in Fig. 5, and compression interface is shown in Fig. 6. Repeated lifting and setting of column foot make the timber structure be a self-centering structure through self-weight.

Compression deformation and compression interface between column foot and stone base are changing during column rocking. Working states of column rocking without slip can be described in six sub-states according to the shape of compression deformation and compression interface as shown in Figs. 3, 4, 5 and 6. xyz denotes the initial coordinate system. $x^{\prime} y^{\prime} z^{\prime}$ is rotational coordinate system. $O$ is rotational center, whose position coincides with the initial position of the center $O^{\prime}$ of column foot. $\theta$ is rotation angle. $r$ is the radius of column. + is on behalf of positive loading.

Loading configurations of the six sub-states in the positive loading process are as follows:

Fig. 4 Compression interface of column foot without lifting

Fig. 2 Column rocking

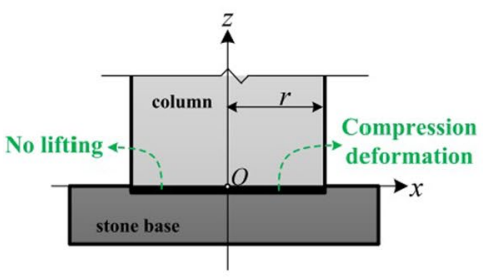

(a) $S_{1}$

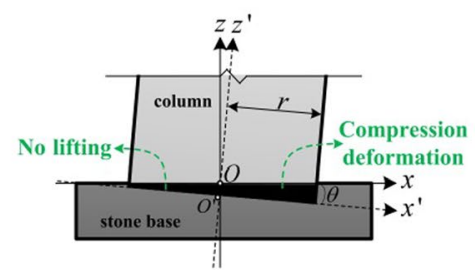

(b) $S_{2}^{+}$

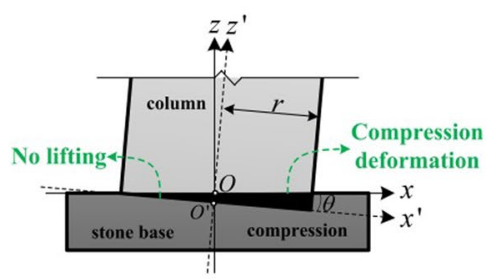

(c) $S_{3}^{+}$

Fig. 3 Compression deformation of column foot without lifting 


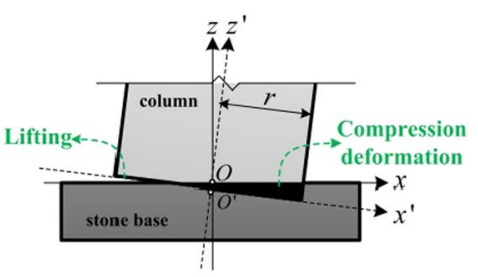

(a) $S_{4}^{+}$

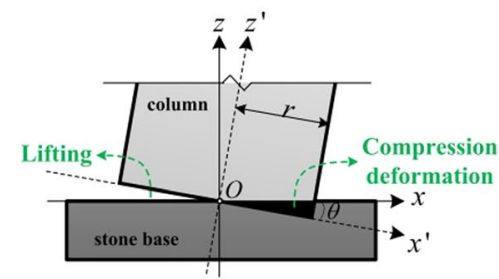

(b) $S_{5}^{+}$

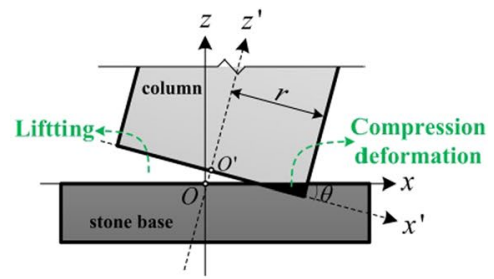

(c) $S_{6}^{+}$

Fig. 5 Compression deformation of column foot with lifting

Fig. 6 Compression interface of column foot with lifting

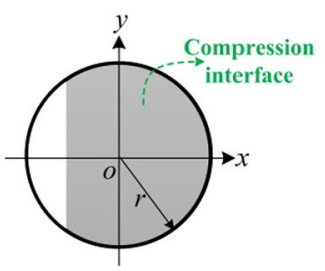

(a) $S_{4}^{+}$

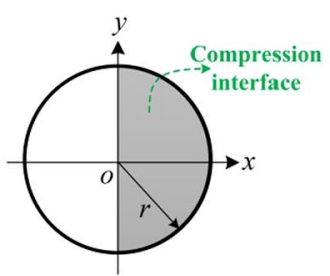

(b) $S_{5}^{+}$

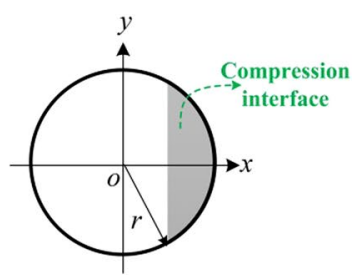

(c) $S_{6}^{+}$
$S_{1}$ : Initial state with only vertical load acting at the top of column without horizontal load. Column foot and stone base contact with each other totally.

$S_{2}^{+}$: Column foot and stone base contact with each other totally. Compression deformation at the right edge of column foot is larger than that of left edge.

$S_{3}^{+}$: Column foot and stone base is not separated, but compression deformation is zero in the left edge of column foot. This is the critical state of lifting of column foot.

$S_{4}^{+}$: Lifting at one side and compression at other side occur to column foot. Compression stress appears at large cross section of column foot.

$S_{5}^{+}$: Compression stress appears at half cross section of column foot. This is the critical state of large and small cross section with compression stress.

$S_{6}^{+}$: Compression stress appears at small cross section of column foot, and compression interface is mainly located in the edge of column foot.

\section{Constitutive relation of timber parallel to grain}

Column foot mainly depends on the timber parallel to grain to bear compression force under vertical load. Therefore, the derivation of theoretical model mainly uses the stress-strain relationship of timber parallel to grain. Due to that the stress on the weakening segment decreases little, the weakening segment can be taken as a horizontal line, and the stress-strain relationship can be simplified to the bilinear constitutive model [19]. Shown in Fig. 7,

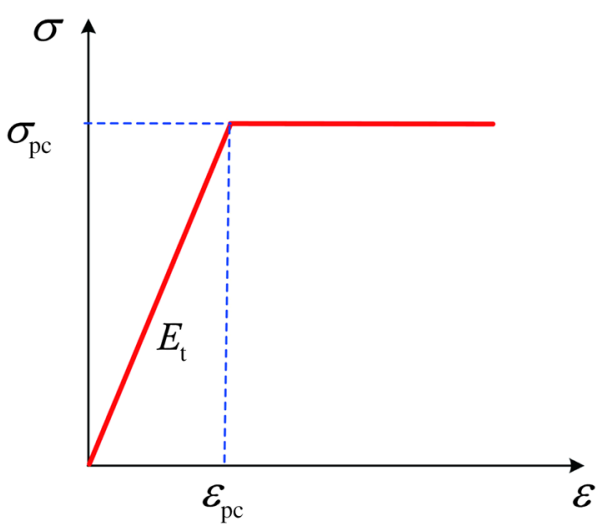

Fig. 7 Constitutive model of timber with compression parallel to grain

compressive stress of timber parallel to the grain increases with the increase of strain initially. After achieving the peak stress $\sigma_{\mathrm{pc}}$, the compressive stress of timber will keep constant.

The stress-strain relationship of timber with compression parallel to grain is

$\left\{\begin{array}{ll}\sigma_{\mathrm{e}}=E_{\mathrm{t}} \varepsilon, & \varepsilon \leqslant \varepsilon_{\mathrm{pc}} \\ \sigma_{\mathrm{p}}=\sigma_{\mathrm{pc}}, & \varepsilon>\varepsilon_{\mathrm{pc}}\end{array}\right.$,

where $\sigma_{\mathrm{e}}$ and $\sigma_{\mathrm{p}}$ are the compressive stress in the elastic and plastic stage, respectively. $E_{\mathrm{t}}$ is the elastic modulus and $\varepsilon_{\mathrm{pc}}$ is the corresponding strain to the peak stress. 


\section{Stress distributions at the compression interface}

Initially, column foot and stone base contact with each other fully. In this state, compression stress may be in elastic stage due to the large compression interface. When the column rotates and deforms to certain extent, column and stone base will be in partial contact with different compression deformations, and the edge of column foot may be into plastic stage due to the small compression interface. Thus, the material at column foot may be elastic or plastic [20] under vertical and horizontal load. And compression stress distributions of vertical load $q_{i}^{+}(x)(i=1,2, \ldots, 6)$ of the six loading substates of the column at the compression interface may be in the elastic and elasto-plastic stage.

\section{Stress state $S_{1}$}

Compression deformation and stress distributions in stress state $S_{1}$ are shown in Fig. 8. The stress of timber material exhibits a linear distribution. The vertical load is $N$. Compression stress distributions can be obtained as

$q_{1}^{+}(x)=\frac{N}{\pi r^{2}}$.

\section{Stress state $S_{2}^{+}$}

During column rocking with deviating from the upright position, the right side of column foot has maximum compression stress, and left side of column has minimum compression stress. If the stress of right point is smaller than $\sigma_{\mathrm{pc}}$, column foot is in the elastic stage. If the stress of right point is equal to $\sigma_{\mathrm{pc}}$, the edge of column foot has been yield. The stress of
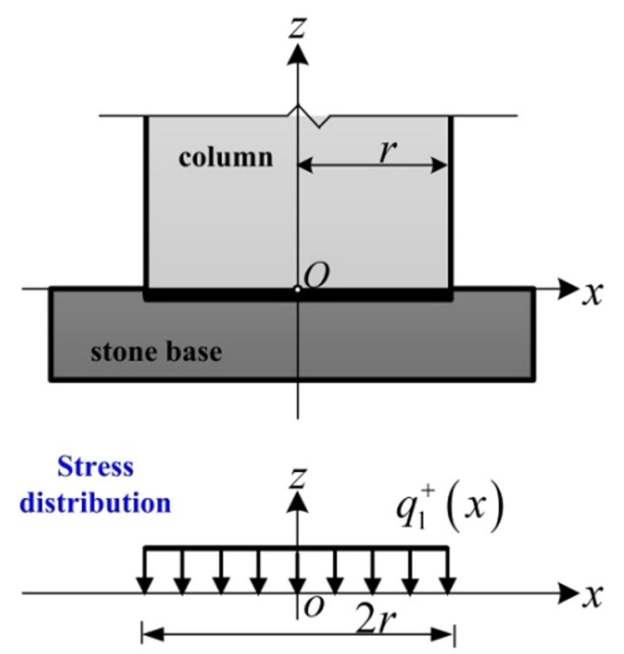

Fig. 8 Compression deformation and compression stress distribution at $S_{1}$ timber material in the compression interface has a bilinear distribution. The peak stress of stress distribution is $\sigma_{\mathrm{pc}}$. Shown in Fig. 9, $L_{\theta}$ is the compression length of column foot, $L_{\theta_{\mathrm{e}}}$ is the elastic compression length of column foot and $L_{\theta_{\mathrm{y}}}$ is the plastic compression length of column foot.

If compression stresses at the compression interface are known, forces and moments can be obtained by integrating the compression stress distributions at the compression interface. Thus, the material constitutive relation, geometric equation and geometrical relation of contact interface are used for establishment of the stress distributions as follows.

Shown in Fig. 9, elastic compression stresses at the right and left edge can be obtained according to Eq. (1) as

$q_{\mathrm{ar}}^{+}=E_{\mathrm{t}} \varepsilon_{\mathrm{ar}}^{+}$,

$q_{\mathrm{al}}^{+}=E_{\mathrm{t}} \varepsilon_{\mathrm{al}}^{+}$,

where $q_{\mathrm{ar}}^{+}$and $\varepsilon_{\mathrm{ar}}^{+}$are the compression stress and strain at the right edge of column foot, respectively, and $q_{\mathrm{al}}^{+}$and $\varepsilon_{\mathrm{al}}^{+}$are the compression stress and strain at the left edge of column foot.

And, compression strains at the right and left edge can be obtained according to geometric equation as

$\varepsilon_{\mathrm{ar}}^{+}=\frac{\Delta h_{\mathrm{ar}}^{+}}{h}$,

$\varepsilon_{\mathrm{al}}^{+}=\frac{\Delta h_{\mathrm{al}}^{+}}{h}$,

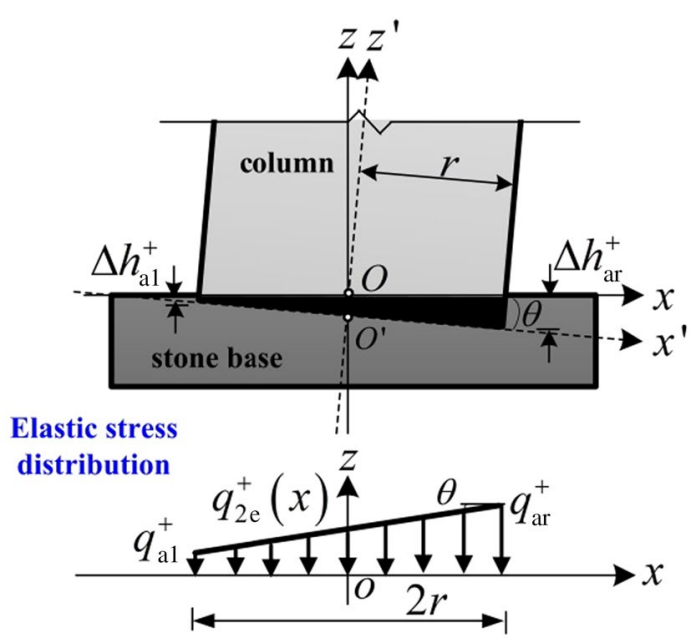

Elasto-plastic stress

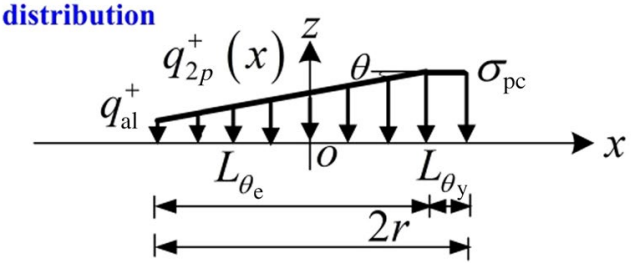

Fig. 9 Compression deformation and compression stress distribution at $S_{2}^{+}$ 
where $\Delta h_{\mathrm{ar}}^{+}$and $\Delta h_{\mathrm{al}}^{+}$are the compression height at the right and left edge of column foot, respectively.

In addition, the equation can be obtained according to geometric proportion relation of compression length and compression height as

$\tan \theta=\frac{\Delta h_{\mathrm{ar}}^{+}-\Delta h_{\mathrm{al}}^{+}}{2 r}$.

Then, the relationship between the stresses at two opposite points of column foot and rotation angle is got by substituting Eqs. (3)-(6) to Eq. (7) as

$q_{\mathrm{ar}}^{+}-q_{\mathrm{al}}^{+}=\frac{2 r \tan \theta E_{\mathrm{t}}}{h}$.

So, the compression stress distribution $q_{2 \mathrm{e}}^{+}(x)$ in elastic stage is given as

$q_{2 \mathrm{e}}^{+}(x)=\frac{\tan \theta E_{\mathrm{t}}}{h}(x-r)+q_{\mathrm{ar}}^{+}$.

Similar to the derivation process of Eq. (8), the relationships among the peak stress $\sigma_{\mathrm{pc}}$, the stress $q_{\mathrm{al}}^{+}$at left edge of column foot and rotation angle in elasto-plastic stage are got as

$\sigma_{\mathrm{pc}}-q_{\mathrm{al}}^{+}=\frac{\tan \theta E_{\mathrm{t}} L_{\theta_{\mathrm{e}}}}{h}$.

So, the compression stress distribution $q_{2 p}^{+}(x)$ in elastoplastic stage is given as

$q_{2 p_{\mathrm{I}}}^{+}(x)=\frac{q_{\mathrm{al}}^{+}-\sigma_{\mathrm{pc}}}{-L_{\theta_{e}}}\left(x-L_{\theta_{\mathrm{e}}}+r\right)+\sigma_{\mathrm{pc}}, \quad-r \leqslant x \leqslant L_{\theta_{\mathrm{e}}}-r$,

$q_{2 p_{\Pi}}^{+}(x)=\sigma_{\mathrm{pc}}, \quad L_{\theta_{\mathrm{e}}}-r<x \leqslant r$.

\section{Stress state $S_{3}^{+}$}

Compression deformation and stress distribution in elastic stage or elasto-plastic stage are shown in Fig. 10. $\Delta h_{\mathrm{br}}^{+}$and $\Delta h_{\mathrm{bl}}^{+}$are the compression height at the right and left edge of column foot, respectively. $\Delta h_{\mathrm{bl}}^{+}$is zero at this state, which is the critical state of $S_{2}^{+}$and $S_{4}^{+}$.

Similar to the derivation process of Eq. (8), the relationship between the stress $q_{\mathrm{br}}^{+}$at the right edge of column foot and rotation angle in elastic stage is got as

$q_{\mathrm{br}}^{+}=\frac{2 r \tan \theta E_{\mathrm{t}}}{h}$,

where $q_{\mathrm{br}}^{+}$is the compression stress at the right edge of column foot.

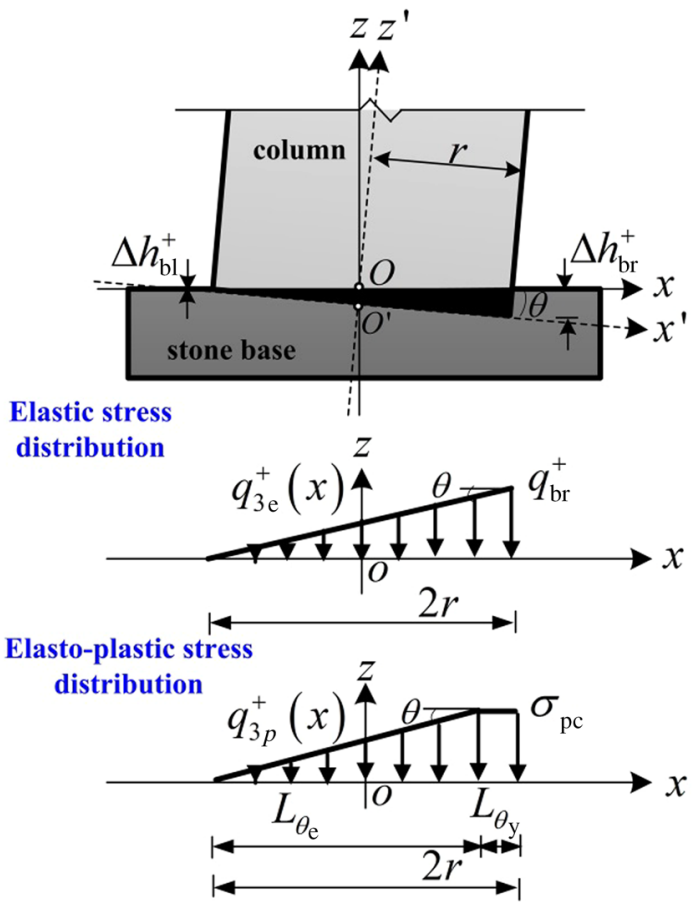

Fig. 10 Compression deformation and compression stress distribution at $S_{3}^{+}$

So, the compression stress distribution $q_{3 \mathrm{e}}^{+}(x)$ in elastic stage is given as

$q_{3 \mathrm{e}}^{+}(x)=\frac{\tan \theta E_{\mathrm{t}}}{h}(x+r)$.

Similar to the derivation process of Eq. (8), the relationship between the peak stress $\sigma_{\mathrm{pc}}$ and rotation angle in elasto-plastic stage is got as

$\sigma_{\mathrm{pc}}=\frac{\tan \theta E_{\mathrm{t}} L_{\theta_{\mathrm{e}}}}{h}$.

So, the compression stress distribution $q_{3 p}^{+}(x)$ in elastoplastic stage is given as

$q_{3 p_{\mathrm{I}}}^{+}(x)=\frac{\sigma_{\mathrm{pc}}}{L_{\theta_{\mathrm{e}}}}(x+r), \quad-r \leqslant x \leqslant L_{\theta_{\mathrm{e}}}-r$,

$q_{3 p_{\Pi}}^{+}(x)=\sigma_{\mathrm{pc}}, \quad L_{\theta_{\mathrm{e}}}-r<x \leqslant r$.

\section{Stress state $S_{4}^{+}$}

Compression deformation and stress distribution in elastic or elasto-plastic stage are shown in Fig. 11. $\Delta h_{\mathrm{cr}}^{+}$is the compression height at the right edge of column foot. 


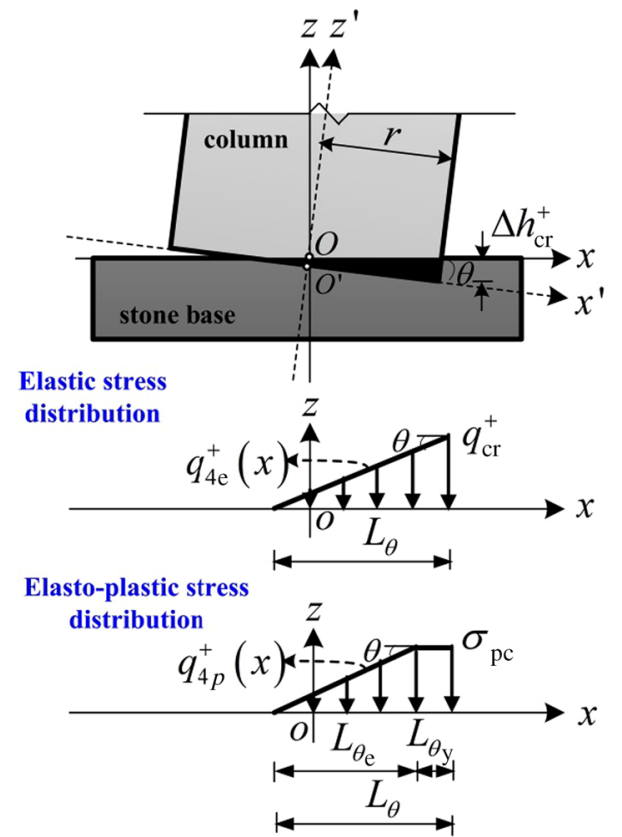

Fig. 11 Compression deformation and compression stress distribution at $S_{4}^{+}$

Similar to the derivation process of Eq. (8), the relationship between the stress $q_{\mathrm{cr}}^{+}$at the right edge of column foot and rotation angle in elastic stage is got as

$q_{\mathrm{cr}}^{+}=\frac{\tan \theta E_{\mathrm{t}} L_{\theta}}{h}$,

where $q_{\mathrm{cr}}^{+}$is the maximum stress at the right edge of column foot.

So, the compression stress distribution $q_{4 \mathrm{e}}^{+}(x)$ in elastic stage is given as

$q_{4 \mathrm{e}}^{+}(x)=\frac{\tan \theta E_{\mathrm{t}}}{h}\left(x-r+L_{\theta}\right)$.

Similar to the derivation process of Eq. (8), the relationship between the peak stress $\sigma_{\mathrm{pc}}$ and rotation angle in elasto-plastic stage is got as

$\sigma_{\mathrm{pc}}=\frac{\tan \theta E_{\mathrm{t}} L_{\theta_{\mathrm{e}}}}{h}$.

So, the compression stress distribution $q_{4 p}^{+}(x)$ in elastoplastic stage is given as

$q_{4 p_{\mathrm{I}}}^{+}(x)=\frac{\sigma_{\mathrm{pc}}}{L_{\theta_{\mathrm{e}}}}\left(x-r+L_{\theta}\right), \quad r-L_{\theta} \leqslant x \leqslant r-L_{\theta_{\mathrm{y}}}$,

$q_{4 p_{\Pi}}^{+}(x)=\sigma_{\mathrm{pc}}, \quad r-L_{\theta_{y}}<x \leqslant r$.

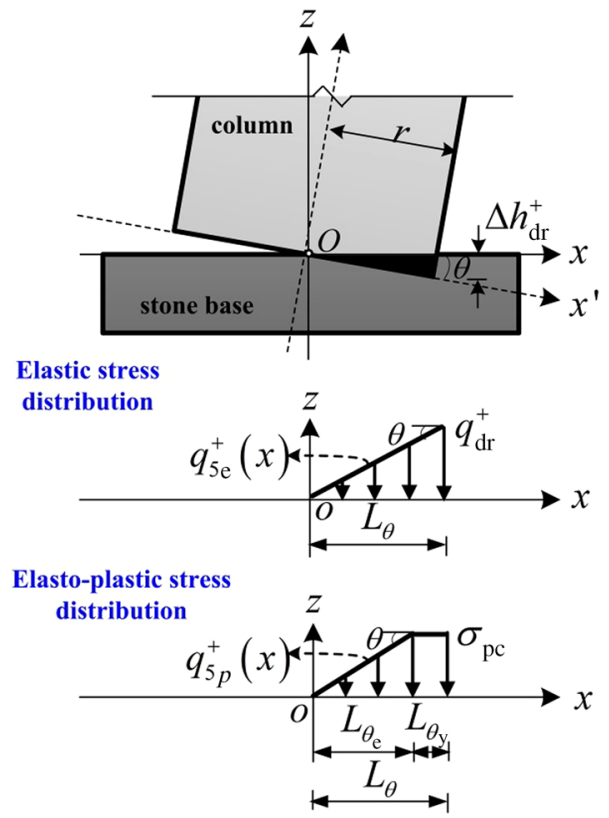

Fig. 12 Compression deformation and compression stress distribution at $S_{5}^{+}$

\section{Stress state $S_{5}^{+}$}

Compression deformation and stress distribution in elastic or elasto-plastic stage are shown in Fig. 12. $\Delta h_{\mathrm{dr}}^{+}$is the compression height at the right edge of column foot.

Similar to the derivation process of Eq. (8), the relationship between the stress $q_{\mathrm{dr}}^{+}$at the right edge of column foot and rotation angle in elastic stage is got as

$q_{\mathrm{dr}}^{+}=\frac{\tan \theta E_{\mathrm{t}} r}{h}$

where $q_{\mathrm{dr}}^{+}$is the maximum stress at the right edge of column foot.

So, the compression stress distribution $q_{5 \mathrm{e}}^{+}(x)$ in elastic stage is given as

$q_{5 \mathrm{e}}^{+}(x)=\frac{\tan \theta E_{\mathrm{t}}}{h} x$.

Similar to the derivation process of Eq. (8), the relationship between the peak stress and rotation angle in elastoplastic stage is got as

$\sigma_{\mathrm{pc}}=\frac{\tan \theta E_{\mathrm{t}} L_{\theta_{\mathrm{e}}}}{h}$.

So, the compression stress distribution $q_{5 p}^{+}(x)$ in elastoplastic stage is given as

$q_{5 p_{\mathrm{I}}}^{+}(x)=\frac{\sigma_{\mathrm{pc}}}{L_{\theta_{\mathrm{e}}}} x, \quad 0 \leqslant x \leqslant L_{\theta_{\mathrm{e}}}$, 
$q_{5 p_{\Pi}}^{+}(x)=\sigma_{\mathrm{pc}}, \quad L_{\theta_{\mathrm{e}}}<x \leqslant r$.

\section{Stress state $S_{6}^{+}$}

Compression deformation and stress distribution in elastic or elasto-plastic stage are shown in Fig. 13. $\Delta h_{\mathrm{er}}^{+}$is the compression height at the right edge of column foot.

Similar as the derivation process of Eq. (8), the relationship between the stress $q_{\mathrm{er}}^{+}$at the right edge of column foot and rotation angle in elastic stage is got as

$q_{\mathrm{er}}^{+}=\frac{\tan \theta E_{\mathrm{t}} L_{\theta}}{h}$,

where $q_{\mathrm{er}}^{+}$is the maximum stress at the right edge of column foot.

So, the compression stress distribution $q_{6 \mathrm{e}}^{+}(x)$ in elastic stage is given as

$q_{6 \mathrm{e}}^{+}(x)=\frac{\tan \theta E_{\mathrm{t}}}{h}\left(x-r+L_{\theta}\right)$.

Similar to the derivation process of Eq. (8), the relationship between the peak stress $\sigma_{\mathrm{pc}}$ and rotation angle in elasto-plastic stage is got as

$\sigma_{\mathrm{pc}}=\frac{\tan \theta E_{\mathrm{t}} L_{\theta_{\mathrm{e}}}}{h}$

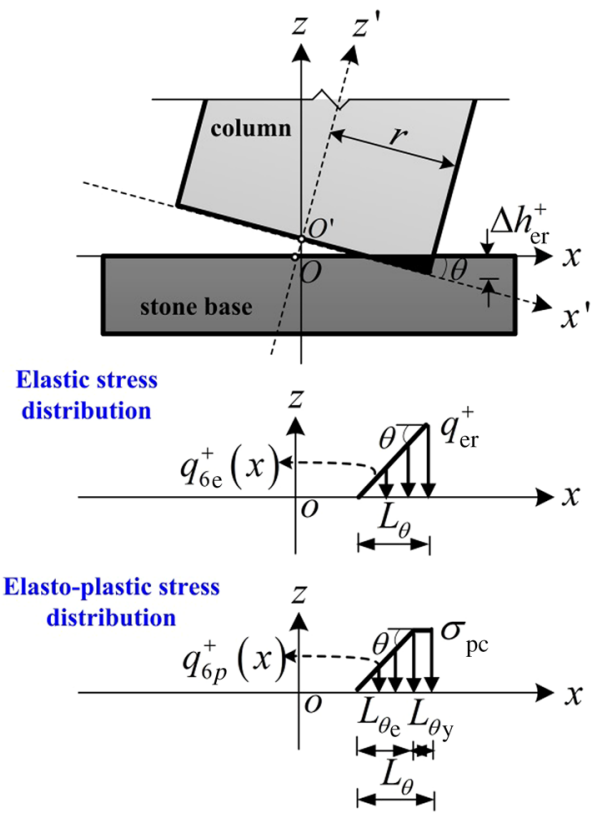

Fig. 13 Compression deformation and compression stress distribution at $S_{6}^{+}$
So, the compression stress distribution $q_{6 p}^{+}(x)$ in elastoplastic stage is given as

$q_{6 p_{\mathrm{I}}}^{+}(x)=\frac{\sigma_{\mathrm{pc}}}{L_{\theta_{\mathrm{e}}}}\left(x-r+L_{\theta}\right), \quad r-L_{\theta} \leqslant x \leqslant r-L_{\theta_{\mathrm{y}}}$,

$q_{6 p_{\Pi}}^{+}(x)=\sigma_{\mathrm{pc}}, \quad r-L_{\theta_{\mathrm{y}}}<x \leqslant r$.

\section{Summary on the resisting compression stress distributions}

Resisting compression stress distributions $w_{i}^{+}(x),(i=1,2, \ldots, 6)$ at the compression interface are equal but opposite to the compression stress distributions $q_{i}^{+}(x),(i=1,2, \ldots, 6)$ from the column foot. Resisting compression stress distributions at $S_{1}$ is

$w_{1}^{+}(x)=\frac{N}{\pi r^{2}}$.

And, resisting compression stress distributions $w_{i}^{+}(x)$ at $S_{i}^{+}(i=2, \ldots, 6)$ are summarized and shown in Table 1.

\section{Theoretical model of restoring moment at column foot}

\section{Restoring moment of column foot at $S_{i}^{+}$}

When column rocks under periodic load, compression reaction force $R$ and compression friction force $F$ are generated at the compression interface shown in Fig. 14. They resist the vertical and horizontal loads acting on the column. Moments caused by these forces are denoted as the restoring moment $M_{\mathrm{bc}}^{+}$of the column foot joint. Compression reaction force, compression friction force, restoring moment at the stress state $S_{i}^{+}$are denoted by $R_{i}^{+}, F_{i}^{+}$and $M_{\mathrm{bc}_{i}}^{+}$with $(i=1,2,3,4,5,6)$, respectively.

Compression reaction force $R_{1}^{+}$is equal to the vertical load $N$ and compression friction force $F_{1}^{+}$is equal to horizontal load $P_{1}$ from force equilibrium. Restoring moment at $S_{1}$ is given as

$M_{\mathrm{bc}_{1}}^{+}=0$

And, compression reaction forces $R_{i}^{+}$and restoring moments $M_{\mathrm{bc}_{i}}^{+}$at $S_{i}^{+}(i=2, \ldots, 6)$ can be obtained by integrating the resisting compression stress distribution on the compression interface [21], which is shown in the Table 2. 
Table 1 Resisting compression stress distributions

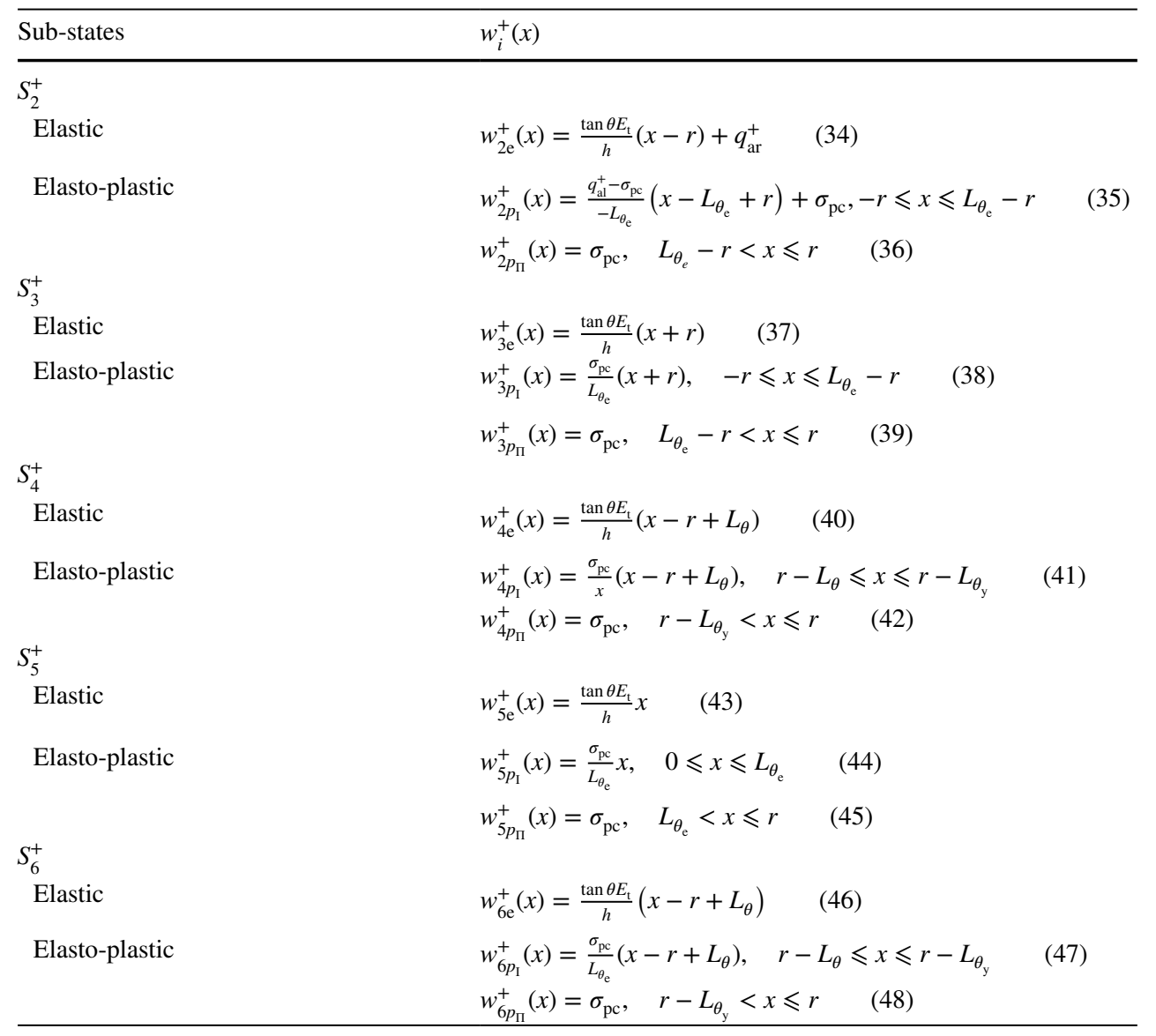

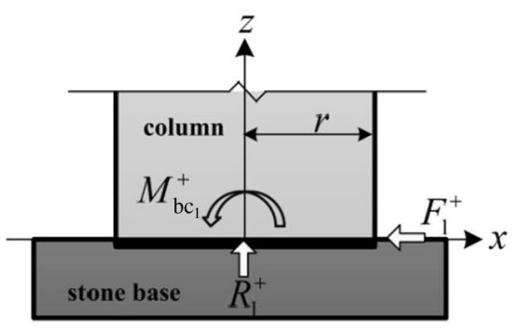

(a) $S_{1}$

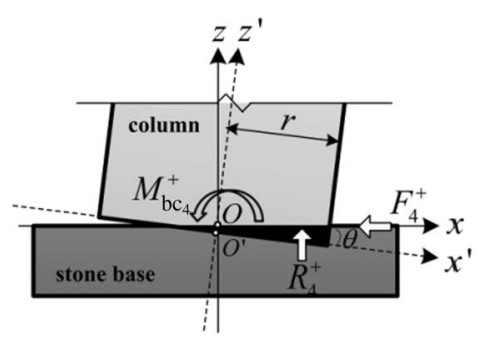

(d) $S_{4}^{+}$

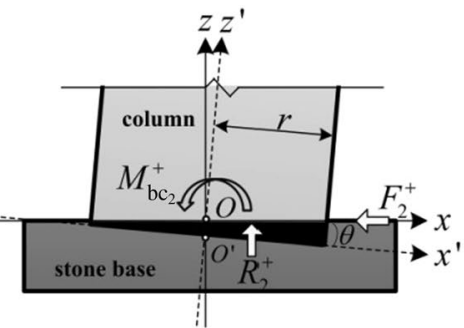

(b) $S_{2}^{+}$

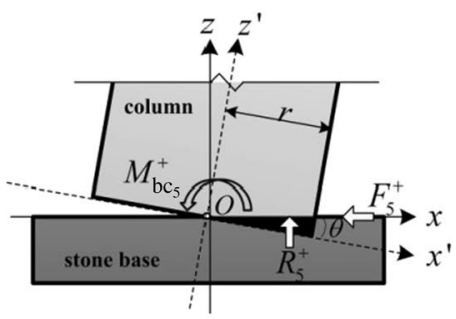

(e) $S_{5}^{+}$

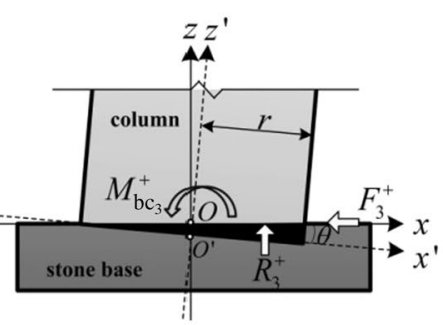

(c) $S_{3}^{+}$

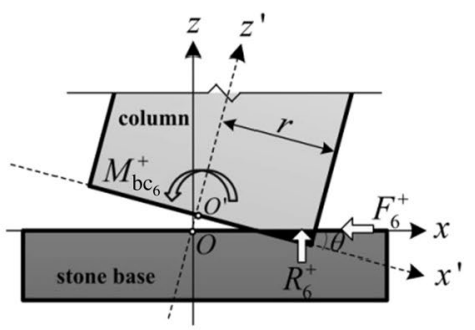

(f) $S_{6}^{+}$

Fig. 14 Force system at six sub-states 
Table 2 Restoring force and moment of column foot

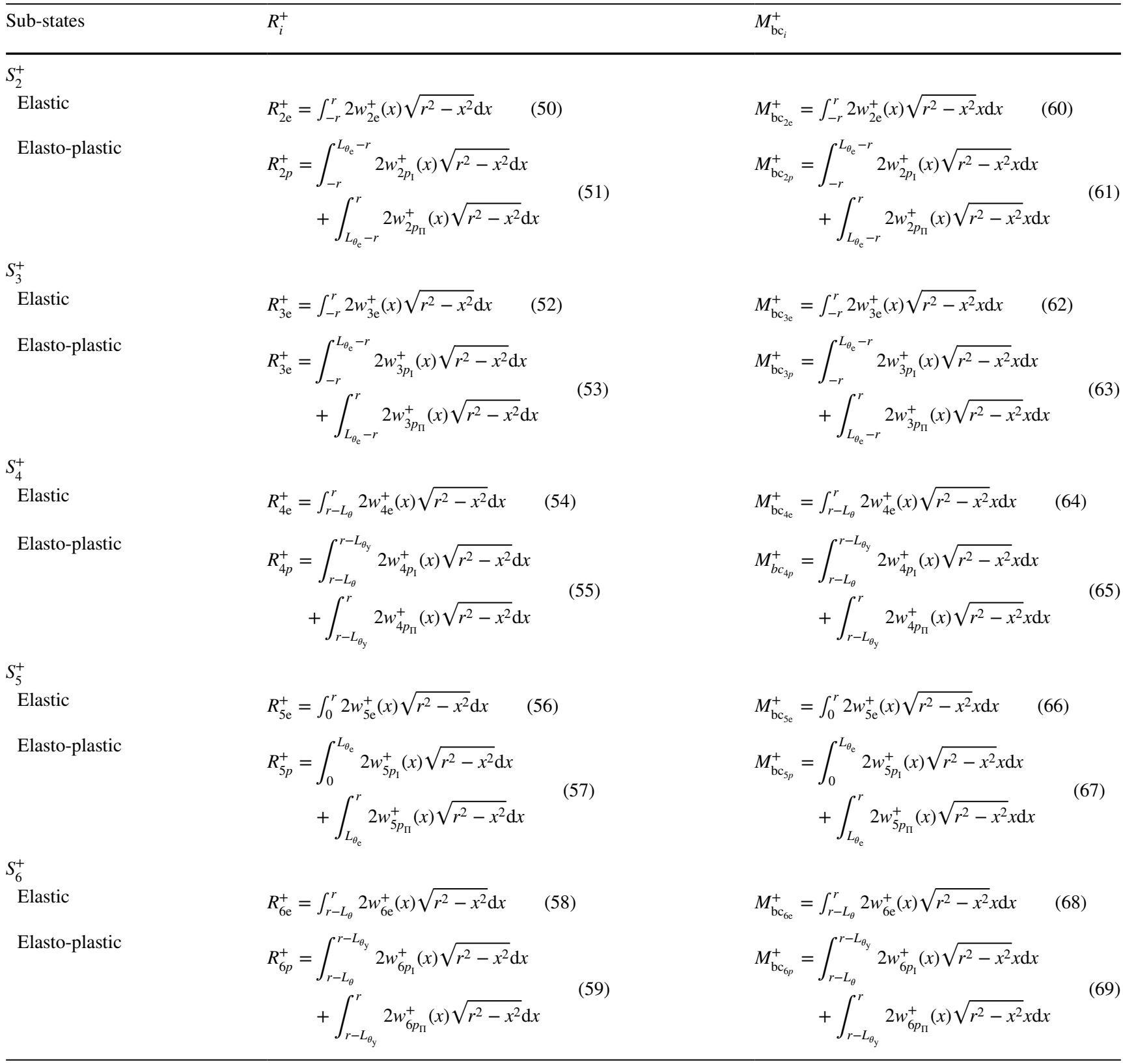

\section{Force system of column}

Before rotation occurs, vertical load is applied to the top center of the column. Once rotation of the column occurs, the contact surface of the column and beam could become partial compression. However, according to the results of the shaking table tests and the static lateral loading tests on full-scale models of traditional wooden frames, the restoring force of a wooden structure consists of two parts: one is the resistant bending moments from the tie beams and another is the restoring forces at the column top and bottom due to rocking. When the deformation is small, the restoring force due to column rocking is the major part of the total restoring force.
With the deformation increasing, the bending moments from the tie beams become more important [11]. In this study, the theoretical model and rotational behaviors of column foot is mainly analyzed under the small horizontal deformation, and the partial compression at the top of the column can be neglected. In addition, vertical load acting on the top center of the column is adopted on the local compression experiment of column conducted by Lee [14] and the numerical simulation conducted by Wan [22]. Thus vertical load can be assumed to be applied to the top center of column.

Shown in Fig. 15, the balance equation of vertical force is $R^{+}=N$ 
Fig. 15 Force system of column

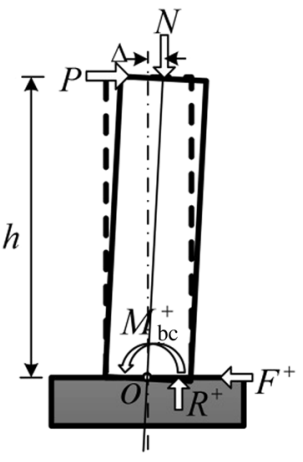

And, column satisfies moment equilibrium conditions at the point $O$ under horizontal load as

$P h+N \Delta=M_{\mathrm{bc}}^{+}$,

where $\Delta$ is the horizontal displacement at the top of column.

Horizontal force and restoring moment can be obtained by simultaneous Eqs. (50)-(59) with Eq. (70) and simultaneous Eqs. (60)-(69) with Eq. (71).

Taking the elastic stage at $S_{6}^{+}$as an example, the balance equation of vertical force and moment at the elastic stage are

$\int_{r-L_{\theta}}^{r} 2 \frac{\tan \theta E_{t}}{h}\left(x-r+L_{\theta}\right) \sqrt{r^{2}-x^{2}} \mathrm{~d} x=N$,

$\int_{r-L_{\theta}}^{r} 2 \frac{\tan \theta E_{t}}{h}\left(x-r+L_{\theta}\right) \sqrt{r^{2}-x^{2}} x \mathrm{~d} x=P h+N h \tan \theta$.

Horizontal force and compression length are unknown at Eqs. (72) and (73), which can be got by simultaneous Eq. (72) with Eq. (73) as

$P_{6 \mathrm{e}}^{+}=\frac{N}{h}\left(r-h \tan \theta-\frac{1}{3} \sqrt{\frac{2 N h}{\tan \theta E_{t} \sqrt{\pi} r}}\right)$.

Due to the complex form of compression length, the expression of $L_{\theta}$ is not given.

Thus, the restoring moment at $S_{6}^{+}$can be obtained as

$M_{\mathrm{bc}_{6 \mathrm{e}}}^{+}=N\left(r-\frac{1}{3} \sqrt{\frac{2 N h}{\tan \theta E_{\mathrm{t}} \sqrt{\pi} r}}\right)$.

In whole, the restoring moment at six sub-states can be obtained at the same way as the derivation process of Eq. (75). Because the expression of restoring moment is complex, the expression cannot be listed and can be got by numerical calculation in Matlab easily.

\section{Finite element analysis}

Finite element model of a typical column foot joint in traditional timber structure is established by ABAQUS to validate the proposed theoretical restoring moment model with horizontal loading.

\section{Finite element model}

The 7th ts'ai column recorded in Ying Zao Fa Shi [23] from the Song Dynasty of China is established. Diameter and height of column are 36f'en and 25f'en, respectively. Each f'en is equal to $10.815 \mathrm{~mm}$, and the size of column under the international units system is as follows: column diameter $=389 \mathrm{~mm}$ and column height $=2758 \mathrm{~mm}$. Stone base is modeled as a $1600 \mathrm{~mm}^{2}$ block with $200 \mathrm{~mm}$ height.

Stresses at the column foot will be changing with rocking of column. The reduction of contact area will lead to the increase of compression stress at the compression interface. Since the compression deformation mainly occurs to timber parallel to grain, the properties of timber perpendicular to grain have less effect on the longitudinal deformation of wood. The material may then be taken as isotropic and elasto-plastic for this study, and the strength of timber parallel to grain can be taken as representative of the strength of timber. Based on the elasto-plastic constitutive model with small deformation, material is assumed to be homogenous and continuous, and the isotropic elasto-plastic model in ABAQUS is chosen as the material model. Material parameters are referred to results from experiments on Pinus koraiensis. Mechanical parameters of timber are as follows: material density $=420 \mathrm{~kg} / \mathrm{m}^{3}$; elastic modulus $=10 \mathrm{GPa}$; Poisson ratio $=0.3$ and yield stress $=34.76 \mathrm{MPa}$. Elastic modulus of stone base is about ten times bigger than that of wood. Poisson ratio of stone base is 0.19 .

Chen had measured the friction coefficients among the different contact interface and different directions of timber, and results showed the contact interface and the directions of timber play little effects to the friction coefficients. The mean value of static friction coefficient of Pinus koraiensis is 0.35 , and the mean value of dynamic friction coefficient is 0.28 [24]. In this simulation, the friction coefficient is taken as 0.35 without considering the difference of dynamic and static friction coefficient due to the slow loading process. That is, coulomb friction model, which has the same static and dynamic friction coefficients, is selected as the interface model to represent the tangential behavior at the column foot in ABAQUS [22].

Vertical load acting on the column is estimated from all the dead loads it supports. Experiences with many 
Fig. 16 Finite element model
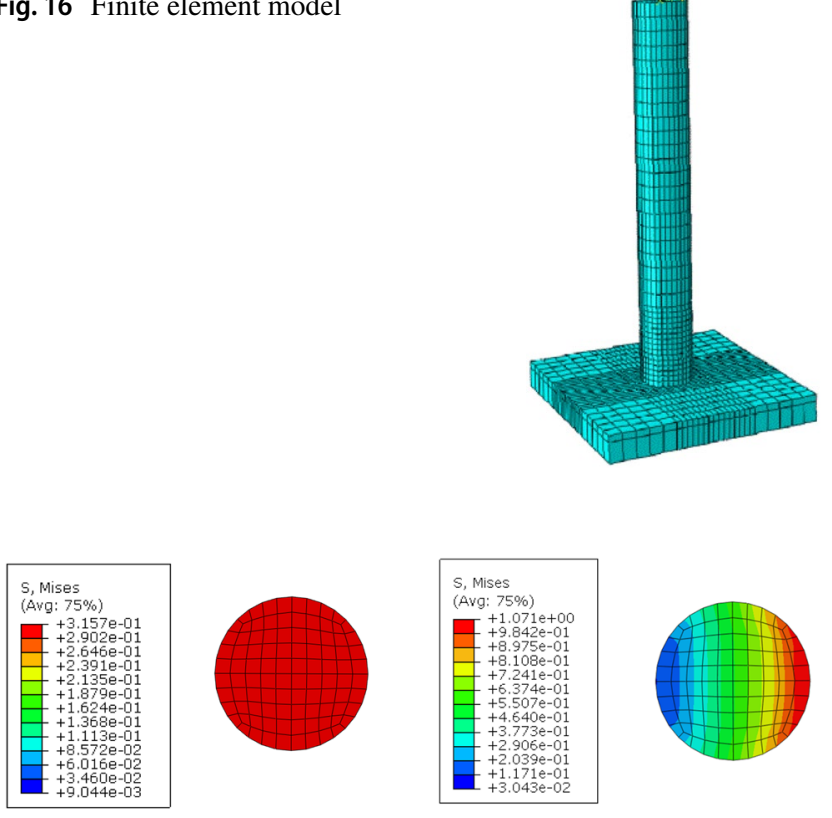

(a) $S_{1}$

(b) $S_{3}^{+}$

Fig. 17 Compression stress distribution of column foot without lifting

historical buildings show that $35 \mathrm{kN}$ is a reasonable estimate including own weight of column. Vertical load is applied to the top center of the column [14]. One-way horizontal displacement is applied at the top of column. The maximum displacement is $190 \mathrm{~mm}$. The bottom of stone base is assumed fixed to the ground.

Column and stone base are divided into different zones in establishing the finite element model. The gridline density at the bottom of column and the top of stone base is denser than those at other parts of column and stone base as shown in Fig. 16. The linear hexahedral element (element type C3D8R) is selected as element for both materials, as this type of element can avoid the "hourglass" phenomenon in the finite element computation [25].
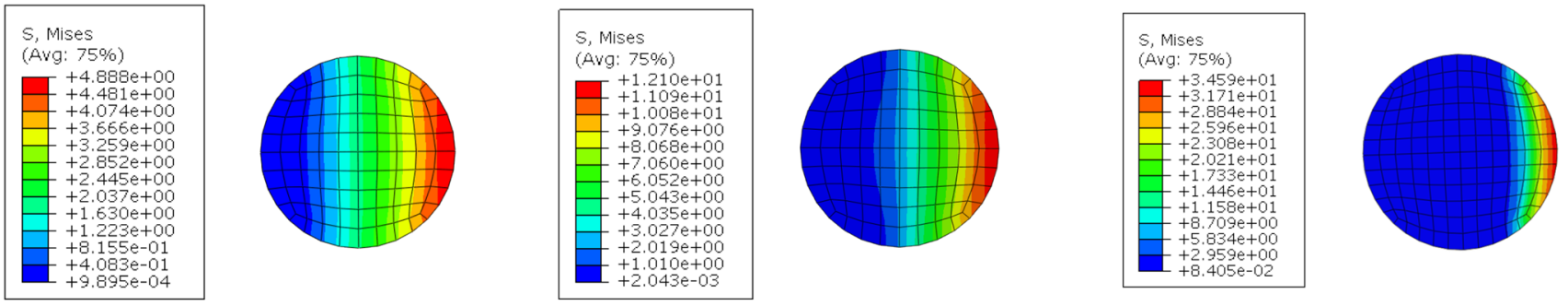

(a) $S_{4}^{+}$

(b) $S_{5}^{+}$

(c) $S_{6}^{+}$

Fig. 18 Compression stress distribution of column foot with lifting 
during rocking. However, owing to small contact areas caused by rotation angle, the compression stresses between the column foot and stone base could reach high levels that up to the ultimate compressive strength of timber. Thus local damages on the column likely occur. Besides, the boundary line between the contact and non-contact areas is almost straight and the stress increment is nearly uniform. Compression interfaces of the numerical model are consistent with those of the conceptual analysis in the section of Compression effect. It is noted that compression stress distributions under negative loading are symmetrically consistent with those under positive loading shown in Figs. 17 and 18, since the absolute value of rotation angles are same.

\section{Comparison between numerical simulation and the proposed model}

The curve of restoring moment and rotation angle can illustrate the rotational capacity of column foot under seismic load. In order to clarify the rotation behaviors of column foot, the curve of restoring moment-rotation angle with six sub-states is shown in Fig. 19. Both the simulated and theoretical curves are close to each other. The trend of variation of curves from both the proposed model and the finite element modeling is noted consistent.

The simulated model is drawn by red line, which can be obtained and extracted from the results of finite element analysis directly. The theoretical model is drawn by black line, which can be calculated by the previous theoretical derivation and drawn with feature points and scatter points. The feature points include the restoring moment and rotation angle at $S_{1}, S_{3}^{+}$and $S_{5}^{+}$. Such as critical rotation angle and restoring moment in elastic stage at $S_{3}^{+}$can be obtained as $\tan \theta_{3 e}^{+}=\frac{N h}{E_{\mathrm{t}} \pi r^{3}}$ and $M_{3 e}^{+}=\frac{N r}{4}$ by simultaneous Eq. (52) with

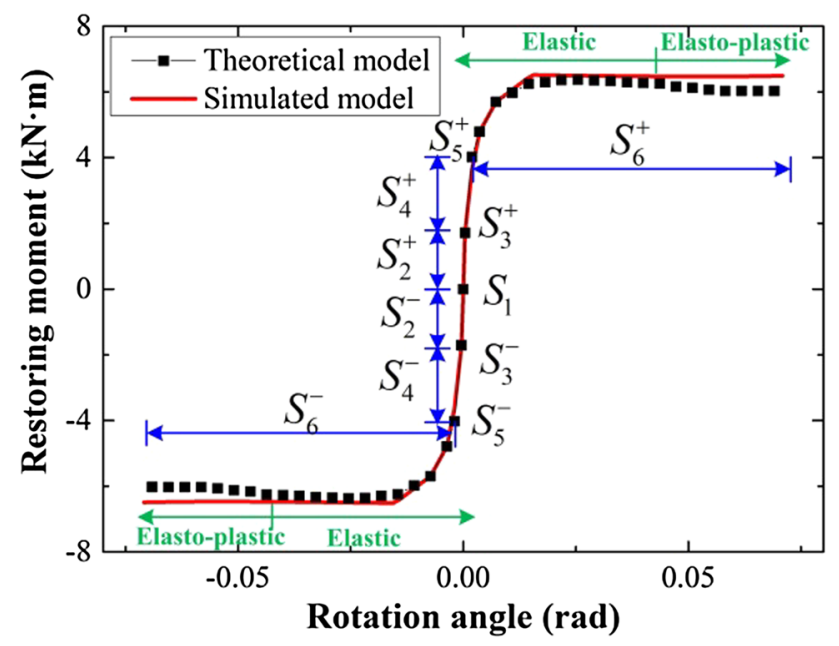

Fig. 19 Theoretical and simulated curve of restoring moment and rotation angle
Eq. (70) and simultaneous Eq. (62) with Eq. (71). Similarly, critical rotation angle in elastic stage at $S_{5}^{+}$can be obtained as $\tan \theta_{5 e}^{+}=\frac{3 N h}{2 E_{\mathrm{t}}{ }^{3}}$ and $M_{5 e}^{+}=\frac{3 \pi N r}{16}$ by simultaneous Eq. (56) with Eq. (70) and simultaneous Eq. (66) with Eq. (71). In addition, scatter points include the restoring moment and rotation angle can be got by substituting horizontal displacement $\Delta=10,20, \ldots, 190 \mathrm{~mm}$ to the proposed model to get the theoretical curve. The elastic and elasto-plastic stage have been noted in the Fig. 19. There is no plastic deformation at $S_{1}$ to $S_{5}^{+}$, and plastic deformation mainly occurs to the column foot at $S_{6}^{+}$due to the small compression interface.

The curve of restoring moment and rotation angle of column foot joint has a reverse $\mathrm{Z}$ shape and anti-symmetric at positive and negative loading in Fig. 19, which has the similar tendency with the results of local compression of test [14]. The initial restoring moment is noted linear and increases rapidly, which shows column foot has a high resistance to small rotation angle. The reason is that compression interface decreases, which can lead to the compression reaction force move to the column edge quickly. The rapid movement of the compression reaction force makes the restoring moment increase rapidly. Besides, the compression stress is the elastic stage and isn't up to the ultimate compression due to large compression interface. The curve is no longer linear after $0.01 \mathrm{rad}$ and restoring moment shows a slow rising trend. The main reason is that the compression interface and the action point of the compression reaction force are close to the edge of column. Changing of the compression interface leads to small changing of the action point of compression reaction force, which causes small changing of restoring moment. Then, the restoring moment almost remains the same value after $0.015 \mathrm{rad}$, that is because the compression interface is located at the edge of column foot and the changing of compression interface cannot cause changing of action point of the compression force any more. Restoring moment of column foot remains to be positive and active in preventing the column from collapse at the maximum rotation angle, which shows column foot joint has certain amount of restoring moment during column rocking to resist the overturning of structure under lateral load.

\section{Discussions}

Good agreement can be found between simulated and theoretical model, and thus the theoretical model and assumptions can be regarded as valid to some extent. However, the accuracy of the proposed model is not sufficient. It should be noted that there are some assumptions in the derivation of the theoretical model and the simulated model including the simplified constitutive model of timber parallel to the 
grain and the position of vertical load, which is convenient for the analysis.

For the first assumption, the bilinear constitutive model made little difference to the compression stress distributions in the elastic stage. But, the simplified model has certain effects to the compression stress distribution in the elastoplastic stage. The diagrams of real and simplified stress distributions are shown in Fig. 20 at the $S_{3}^{+}$stage. Compression stresses at the edge of column foot was overestimated due to the horizontal line instead of the weakening segment. In addition, the elastic compression length $L_{\theta_{\mathrm{e}}}$ was underestimated and the plastic compression length $L_{\theta_{y}}$ was overestimated according to the balance of the vertical load. The theoretical moment obtained by the simplified model was overestimated compared with that of real model due to the action point of compression reaction force is closer to the edge of column foot than that of real model. The theoretical moments in the other sub-states are the similar with that of $S_{3}^{+}$.

For the second assumption, the position of vertical load is assumed to be applied at the top center of column. Before column rocking, the assumption is reasonable. But once rotation of the column occurs, the position of vertical load deviates from the center of column head. Because the theoretical model is mainly obtained based on the small rotation angle, the offset distance of vertical load is small. While the position of vertical load makes a little effects on the restoring moment. Equation (71) changes into $P h+N\left(\Delta-\Delta_{\mathrm{d}}\right)=M_{\mathrm{bc}}^{+}$ with taking the partial compression into consideration. $\Delta_{\mathrm{d}}$ is the offset distance of vertical load. The theoretical moment may be overestimated without considering the partial compression based on the above formula. All in all, it should be noted that the above assumptions should be improved in the

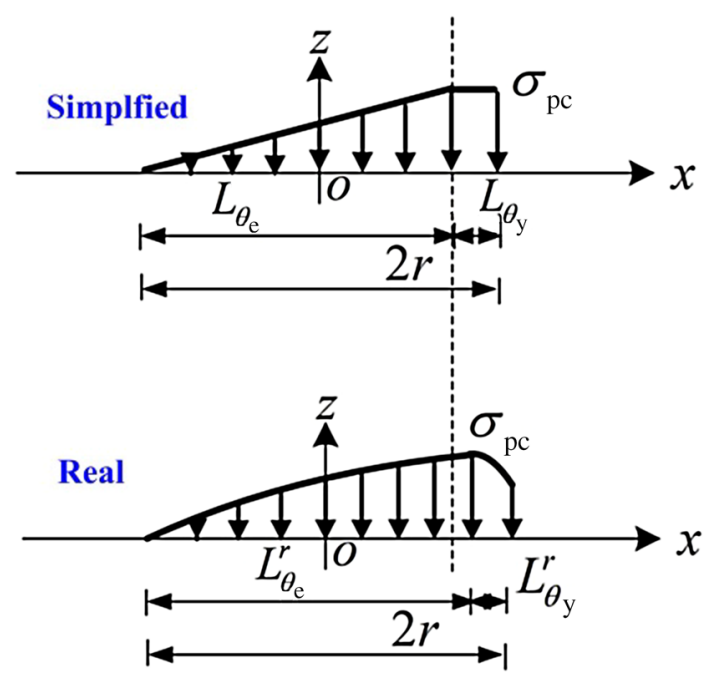

Fig. 20 Real and simplified compression stress distribution at $S_{3}^{+}$ future study in order to make the theoretical model more accurate.

\section{Conclusions}

The rotational behavior of column foot in traditional timber structure is analyzed in this paper. Under cyclic load, column is subjected to lift and reset called "column rocking". Column rotates around the edge of column foot. During rocking, column foot has compression deformation under vertical load, and the material at column foot may be in elastic stage or elasto-plastic stage. Compression stress occurs at the contact interface between column and stone base. Compression reaction force and friction force are generated at the interface between column foot and stone base, as well restoring moment occurs to column foot.

The theoretical model of the restoring moment at column foot is proposed for the different sub-states of column foot with consideration the compression effect, and derived based on constitutive equations, geometric equation, geometrical relationship and equilibrium equation. The proposed model generally shows good agreement with results of numerical simulation, indicating the validity of the theoretical method, and can be considered as a suitable basis for mechanical analyses to predict the structural performance of traditional timber structure. The results of theoretical model and numerical simulation show that column foot joint has certain amount of restoring moment during rocking to resist the overturning of structure under lateral load.

Acknowledgements This work is supported by the National Natural Science Foundation of China (nos. 51408038 and 51338001). The authors would also like to thank the research project funding of the 111 Project of China (no. B13002), National Key R\&D Program of China (nos. 2015BAK01B02 and 2017YFC0703505) and the Beijing Natural Science Foundation (no. 8151003).

\section{References}

1. Van de Kuilen JWG (2007) Service life modelling of timber structures. Mater Struct 40:151-161

2. Michal K, Milos D, Jan T, Jaroslav H (2015) Conventional compressive strength parallel to the grain and mechanical resistance of wood against pin penetration and microdrilling established by in-situ semi-destructive devices. Mater Struct 48:3217-3229

3. Vieux-Champagne F, Sieffert Y, Grange S, Polastri A, Ceccotti A, Daudeville L (2014) Experimental analysis of seismic resistance of timber-framed structures with stones and earth infill. Eng Struct 69:102-115

4. Zhao HT, Zhang FL, Xue JY, Xie QF, Zhang XC, Ma H (2012) Research review on structural performance of ancient timber structure (in Chinese). J Buil Struct 33(8):1-10

5. Mashima K (1930) Earthquake and architecture. Maruzen Co., Tokyo 
6. Maeda T (2008) Column rocking behaviour of traditional wooden building in Japan. The World Conference on Timber Engineering, Miyazaki, Japan

7. Ban S (1941) Study on statics for structures of temple and shrine part-1. Technical papers of are annual meeting, architectural institute of Japan (A.I.J), vol 34, pp 252-258

8. Kawai N (1996) Column rocking resistance in Japanese traditional timber buildings. In: Proceedings of the international wood engineering conference. Vol.1,10, New Orleans, pp 186-190

9. Maeno M, Saito S, Suzuki Y (2007) Evaluation of equilibrium of force acting on column and restoring force due to column rocking by full scale tests of traditional wooden frames. J Struct Constr Eng 72(615):153-160

10. Nagase T, Saburi K (1999) Static and dynamic analyses of Japanese Traditional Timber Buildings (in Japanese). In: Proceeding of inter-national seminar on numerical analysis in solid and fluid dynamics, Osaka, pp 421-427

11. Maeno M, Suzuki Y, Ohshita T, Kitahara A (2004) Seismic response characteristics of traditional wooden frame by full-scale dynamic and static tests. In: The 13th world conference on earthquake engineering, Vancouver, B.C., Canada, Aug. 1-6 2004

12. Yao K, Zhao HT (2006) Study on the mechanism of sliding friction shock isolation between timber column and plinth in historical timber building (in Chinese). Eng Mech 23(8):127-131

13. Zhang FL, Zhao HT, Xue JY, Xie QF, Sun Y, Luo Z (2013) Lateral load-resisting analysis and experimental verification of ancient timber based on swing-columns principle (in Chinese). Ind Constr 43(10):54-60

14. Lee D, Araki Y, Endo T, Yoshida N, Uetani K (2009) Modelling of column base for traditional timber buildings based on local compression experiments at contact surface between column base and foundation stone (in Japanese). J Struct Constr Eng 74(639):865-872

15. Zhang PC (2003) Study on structure and its seismic behavior development of Chinese ancient timber structure building (in Chinese). PhD thesis, Department of Civil Engineering, Xi' an University of Architecture \& Technology, Xi' an, China
16. Dogangun A, Tuluk O, Livaoglu R, Acar R (2006) Traditional wooden building and their damages during earthquakes in Turkey. Eng Fail Anal 13(6):981-996

17. Ogawa K, Sasaki Y, Yamasaki M (2015) Theoretical modelling and experimental study of Japanese "Watari-ago" joints. J Wood Sci 61:481-491

18. Ogawa K, Sasaki Y, Yamasaki M (2016) Theoretical estimation of the mechanical performance of traditional mortise-tenon joint involving a gap. J Wood Sci 62:242-250

19. Chen ZY, Zhu EC, Pan JL (2011) Numerical simulation of mechanical behaviour of wood under complex stress (in Chinese). Chin J Comput Mech 28(4):629-635

20. Mackenzie-Helnwein P, Mullner HW, Eberhardsteiner J, Mang HA (2005) Analysis of layered wooden shells using an orthotropic elasto-plastic model for multi-axial loading of clear spruce wood. Comput Method Appl Mech Eng 194(21-24):2661-2685

21. Tanahashi H, Suzuki Y (2012) Basic concept and general formulation of restoring force characteristics of traditional wooden joints. The World Conference on Timber Engineering, Auckland, pp 378-387

22. Wan J (2015) Static and dynamic FE analyses of single column frictional system in the 3rd and 7th ts'si recording in Yingzaofashi (in Chinese). Master thesis. Taiyuan University of Technology. Shanxi, China. http://kns.cnki.net/KCMS/detail/detail.aspx?dbc ode $=$ CMFD \&dbname $=$ CMFD201502\&filena me $=1015601919$. nh\&v=MjA0NzBqTnBwRWJQSVI4ZVgxTHV4WVM3RGgxV DNxVHJXTTFGckNVUkwyZll1ZG1GeWpuVjdySIZGMjZHN1 c0SDk=.pdf. Accessed 29 Jun 2015

23. Li J (2006) Ying Zao Fa Shi (in Chinese). China Bookstore Press, Beijing

24. Chen ZY (2011) Behaviour of typical joints and the structure of Yingxian wood pagoda (in Chinese). PhD thesis, Harbin Institute of Technology, Harbin, China

25. Shi YP, Zhou YR (2006) The example explanation of finite element analysis by ABAQUS (in Chinese). China Machine Press, Beijing 